\title{
"Triple Bottom Line" of the 12th Five Year Plan: A Pathway for China's Identity Construction through Energy Consumption
}

\author{
Ebenezer Impriam Amponsah ${ }^{1} \quad$ Desmond Oklikah Ofori ${ }^{2 *} \quad$ Abdul-Rahim Abdulai ${ }^{3}$ \\ 1.Department of Sociology, Hohai University, Nanjing City, China, 211100 \\ 2.Department of History, University of Guelph, Ontario-Canada \\ 3.Department of Geography, Environment \& Geomatics, University of Guelph, Ontario-Canada
}

\begin{abstract}
Change and reforms in the energy structure is realizable when new and renewable sources are developed with the mandate to support a policy on larger-scale basis. Energy consumption and economic development are household names in China and effects of both phenomena are present. For the purpose of achieving a green growth, China's ambitious Twelfth Five Year Plan (2011-2015) was set to develop a new and renewable energy but faced several challenges due to the diversity and instability of new and renewable energy resources. The plan further stands for the first time, as a national plan that shifts away from development agenda with a focus toward a pattern of green growth. Taking the theory of triple bottom line of social equity, economic and environmental development as a base of the 12th FYP, this paper has analyzed the impact of the plan in achieving a green growth and an identity construction in China
\end{abstract}

Keywords: Energy Consumption, Green Growth, Identity Construction, Triple Bottom line, Sustainability DOI: $10.7176 / \mathrm{JRDM} / 69-07$

Publication date:September $30^{\text {th }} 2020$

\section{Introduction}

Energy is critical for the sustenance of human societies, especially in this contemporary time, as is a basic material safeguard of society. Bilgen (2014) emphasizes that energy is essential for economic and social development and the improvement of life. Energy transitions are central in every significant progress made in civilization as one energy source is substituted by another. Starting in the mid-19th century, for an accelerated form of development, the world moved into exploitation of oil and gas as this form of energy consumption is a key lever to achieve more rapid development (Rennings et al. 2012). As a result of the increased in oil and gas energy consumption, the society gradually entered the Oil and Gas Age. However, the long-term exploitation and utilization of fossil energy have resulted in serious ecological and environmental problems in many countries, including China, resulting in calls for another transition. The primary energy consumption of China includes five types, i.e., coal, oil, gas, nuclear and renewables, which are mainly used in the four sectors, i.e., transport, industry, building and others (Bilgen 2014).

Ma and Chen (2016) notes that, in China, if the energy-saving and low-carbon mode is adopted for economic and social development, then energy-related carbon dioxide emissions will peak around 2030, with the emission peak coming as early as 2025 . These factors bring forth tremendous challenges to the energy structure dominated by fossil energy. As a result of this and to ensure the sustenance of the society, the Twelfth Five Year Plan (20112015) of China was implemented as a crucial plan that seeks to achieve a green growth. This paper examines China's energy future under this crucial five-year plan.

The onus correspondingly lies on the government to ensure the social equity, economic and environmental development of every citizen. This goal can only be achieved by implementing policies which affects citizens in every part of the country. For this reason, the 12th Five-Year Plan was taken further, though outdates the stipulated years by a much more detailed sectoral and provincial FYPs with specific targets, measures and initiatives, as well as later regulations, policies and guidance. Central and local governments' ministries and departments, regions and industries set clear targets and responsibilities, specified emission reduction programs, and developed appropriate work programs. In concurrence, the plan highlights three very important areas which today has given China a unique identity in the world.

\section{The Triple Bottom Line}

Sustainability is a non-negotiable element in many areas such as businesses, cooperate bodies and governments due to its depth of importance. Putting the term within the context of the environment, Arora (2018) notes that environmental sustainability is one of the biggest issues faced by mankind at present as population increase along with an escalation in anthropogenic activities has raised several questions on the sustainability of natural resources on our planet. In definition, Hart and Milsten (2003) defined sustainability as the expectations of improving the social and environmental performance of the present generation without comprising the ability of future generations to meet their social and environmental needs. According to Slaper \& Hall (2011), the triple bottom line is an accounting framework with three parts: social, environmental (or ecological) and financial. Many 
organizations have adopted the TBL framework to evaluate their performance in a broader perspective to create greater business values. The triple bottom line (TBL) is a sustainability-related construct that was coined in 1994 by Elkington (2018); and was targeted toward corporations like energy producing companies. The TBL agenda puts a consistent and balanced focus on the economic, social, and environmental value provided by organizations and this is summarized in the phrase, "people, planet, and profit" to describe the triple bottom line.

\subsection{Economic sustainability}

In the Triple Bottom Line approach, economic sustainability is not simply the traditional corporate capital. The economic capital under the Triple Bottom Line model should be measured in terms of how much of an impact a business or organization set up has on its economic environment and political economy. Spangenberg, (2005) adds that economic sustainability of the TBL pertains to the capability of the economy as one of the sub-systems of sustainability to survive and evolve into the future. The economic line ties the growth of the socio-political structures and organizations to the growth of the economy and how well it contributes to support it.

\subsection{Social sustainability}

The social sustainability of the TBL focuses on the interaction between the community and the organizations. The tenet addresses issues related to community involvement and initiatives, employee relations, and fair wages (Goel, 2010). The Social bottom line measures an organization's human capital, to have fair and beneficial labour practices through corporate community involvement. It can also be measured based on the impacts a business activity has on the local economy and vice versa.

\subsection{Environmental sustainability}

The environmental sustainability of the Triple Bottom Line takes the approach that the impact of an organizations activities on the environment including the fewer natural resources consumption should move in conjunction with profits of the business. In detail, controlling the environmental bottom line means managing, monitoring, and reporting consumption and waste and emissions for energy consumption and production companies. The environmental line of TBL refers to engaging in practices that do not compromise the environmental resources for future generations and as such promotes/enhances the efficient use of energy recourses, reducing greenhouse gas emissions, and minimizing the ecological footprint (Goel, 2010). Regarding energy consumption, the thoughts about energy efficiency and in this case production and consumption, has become so relevant that energy is now a permanent discussion even among international groups. The expansion in energy consumption has a number of negative side effects, such as the depletion of natural resources (use in energy generation) and pollution. Energy transportation and consumption cause significant impact on the environment, therefore there is the need to discuss and stimulate energy efficiency which the TBL is a good framework to study this phenomenon.

\section{Methodology}

This micro-research benefits from a pool of debates that transpired in relation to the place of energy consumption in China. This paper followed the discussion of China International Protection Exhibition and Conference; Energy Storage China; Clean Energy Expo China; China GPower and Asia-Pacific Bioenergy Exhibition. The discussions that ensued at these programs were tailored towards a review of the successes and failures of the 12th Five Year Plan. Moreover, this study relies on a thorough review of existing literature on the subject to investigate the phenomenon under consideration with the aim of conveying to the reader what knowledge and ideas have been established on the topic, and what the strengths and weaknesses can mean to global energy (re)production and consumption.

\section{China's Identity Construction through Energy Consumption}

There is a great deal of importance when a positive or negative identity of a country is shown to the rest of the world. On this note, energy consumption in China has created an identity as the culture of consumption has changed or diversified. Consumption is no longer about the usage of the product, but rather the consumption of the symbolic meaning of the products or the image (Levy, 1959). Consequently, to ensure the economic prowess and global recognition in the phase of production, a country has to make more choices, as there has been the provision of building blocks with which people communicate who they are and (re)construct their identity (Buhl, 2005), hence China's launch of the 12th Final Year Plan in 2011. Accordingly, this argument emphasizes Sassatelli's (2007, p. 125) "idea that everyone in consumer societies is more open to acquiring the lifestyle and identity they desire runs the risk of painting an imaginary world made of equal opportunity and free selfrealization". It is clear, observing advertisements which celebrate consumption as a sphere of human realization, that a particular type of identity, a certain kind of look, a particular way of being in the world, is put out for the consumptions of the society, thereby creating a certain kind of identity from the symbols seen in advertisement of commodities. 
The above indicates the breadth and depth of the identity concept and how complex it is to deal with a concept so flowing, dynamic and discursive with multiple and continuously (re)negotiable meanings (Csaba \& Bengtsson, 2006). Known as the world's highest producer and consumer of energy precisely coal (CPT, 2016), China has shown a resilience and commitment in achieving a green environment without compromising unprecedented economic growth. At a point in time, due to the high carbon emission leading to an accolade of being the world's largest emitter of greenhouse gases, China faced widespread criticism from the international community. Similarly, there was also an internal pressure to address environmental concerns while maintaining economic growth. By pledging to reduce harmful gas emissions intensity from 60 to $65 \%$ as part of the Paris Agreement. How China manages the emission of toxic gases affects both its ability to emerge as a leader in sustainable development and the broader fight against climate change (CPT, 2018).

The 12th Final Year Plan strengthens China's future socio-economic development strategy and targets, and pathways regarding optimum social, economic and environmental development scenario while constructing a positive identity. The 12th Final Year Plan is unique and very important because of the triple-bottom-line approach it carries and has been the first-year plan to carry such approach in bold steps and achieved success. The preceding year plans have a good bases to achieve more and to further enhance the positive identity China has created through its energy consumption. The details of the triple-bottom-line 12th Final Year Plan and energy consumption is as follows and a reaffirmation of the China's positive identity.

\subsection{Consumption of Energy in China}

Ensuring efficient access to energy is an ongoing and pressing challenge for global development because the consumption of energy systems has important environmental impacts. Historical and current energy systems are dominated by fossil fuels (coal, oil and gas) which produce carbon dioxide (CO2) and other greenhouse gases thereby, becoming the fundamental driver of global climate change. Attaining a balance between economic growth and a sustainable environment provides the ultimate goal of ensuring access to enough sustainable energy to maintain a high standard of living. China with its level of economic growth in the world has earned the country a discussion into the now and then of energy consumption and the role it plays within the global economy.

Chinese consumption in particular, abounds in the media, policy research and among business circles. According to Xin (2019), consumption of clean energy, including natural gas, hydropower, nuclear power and wind power, accounted for $22.1 \%$ of energy consumption in 2018 and up to 1.3 percent compared with the same period in 2017. The World Nuclear Association in China reported in 2007 that since 1980, China's energy production has grown dramatically, as the proportion allocated to domestic consumption. The report goes ahead to indicate that some $80 \%$ of all power is generated from fossil fuel at thermal plants, with about $17 \%$ at hydroelectric installations; only about $2 \%$ is from nuclear energy, mainly from plants located in Guangdong and Zhejiang (World Nuclear Association, 2007). In this regard, the domestic and industrial consumption of energy is worth noting.

\subsubsection{Domestic energy consumption:}

Household energy consumption is a key area of concern in energy consumption especially among populous countries. According to Liu (2011) while China's population was less than $20 \%$ urban in 1980, it was over $52.3 \%$ urbanized by 2012 and for that matter, urbanization has boosted household consumption as urban households tend to be wealthier and thus altering the nature of energy use. During the period of 1992-2007, direct and indirect carbon dioxide (CO2) emissions from household consumption accounted for more than $40 \%$ of all carbon emissions due to primary energy use in China. Śmiech \& Papież, (2014) emphasizes that China is the largest country of energy consumption and carbon dioxide emissions; thus, how to fairly handle the relationship of domestic energy consumption, carbon dioxide and economic growth present a unique opportunity for further discussions and research. The key to energy saving and emissions reduction is effective control of total energy consumption and more efficient use of fossil fuels. However, the efficiency of fossil fuel utilization to produce different products is different. Therefore, China can examine the utilization of different fuels for different products and make a thorough assessment to maximize energy efficiency of different fossils (Cao, 2010). Therefore, there should be efforts in achieving a balance for the continuous sustenance of the environment.

4.1.2 Industrial energy consumption

The large and diverse population of China calls for large firms and production to meet the needs of the market and consequently that also leads to the consumption of more energy. There is a positive correlation between the industrial energy consumption in China and the high economic growth. Economic growth in China significantly is celebrated 70 years of what is literally termed as the "reform and opening-up" or the "New China" in October 2019. According to Brandt (2008), before the reforms, the Chinese economy was dominated by state ownership and central planning. As a result, Walder, (2015) noted that this situation made the Chinese real GDP per capita grow at a rate of $2.9 \%$ per year on average, from 1950 to 1973 albeit with major fluctuations stemming from the Great Leap Forward and the Cultural Revolution. Based on government statistics, China has been the fastest growing economy in the world since the 1980s, with an average annual growth rate of 10\% from 1978 to 2005 
(Kroeber, 2016)

Various forms of pollution have increased as China have industrialized causing widespread environmental and health problems (Wong, 2013). Coal accounts for $70 \%$ of the total energy consumption, and emissions from coal combustion are the major anthropogenic contributors to air pollution in China (Chen \& Yao, 2008). This has translated to cause air pollution to be one of the environmental issues in China (greenhouse gases and sulfur dioxide particulates) from overreliance on coal, which produces acid rain, water shortages. Hays, (2008) advocates for the necessity of better pollution control and billion-dollar cleanup programs to help reduce the growth rate of industrial pollution.

In essence, many factors account for the trio related concepts - energy consumption, industrial production and economic growth - in china. In response to McGrath (2019), China relied on coal as a key step in developing the economy (between 2006-2015) but the push had many negative consequences like choking the air with pollution in many Chinese cities and leading to huge overcapacity. Significantly, the change in lifestyle, taste and preference in China influenced by modernization and westernization is a major contributor. However, it is important to note that the energy industry typically requires large investment, has a long cycle, and possesses strong inertia. No transformation and change in energy structure can be achieved overnight, and such transitions must overcome huge challenges. To achieve this transformation, there is the need for policy guidance and support from governments. As such Andrew-States (2014) contends that ensuring adequate energy supply to sustain economic growth has been a core concern of the Chinese government since 1949 and gives an opportunity for the study into the energy policies.

\subsection{A delve into the 12th Five-year Plan 2011-2015 of China}

There has been a series of a Five-Year Plans surrounding social and economic development initiatives since 1953 in the People's Republic of China. According to Lewis (2011), the 12th Five-Year Plan (FYP) adopted by the Chinese government in March 2011 devoted considerable attention to energy and climate change and establishes a new set of targets and policies for the period of 2011-2015. The United Nations describes China's 12th Five Year Plan (2011-2015) as the first national plan to shift the development agenda decisively toward a pattern of green growth. Out of all the energy conservation policies, the 12th Five-Year Plan period is crucial for building a moderately prosperous society in all respects and for deepening reform and opening up and speeding up the transformation of the pattern of economic development. Among the goals is the quest to gradually establish a carbon trade market.

Key targets include a 16\% reduction in energy intensity (energy consumption per unit of GDP), increasing non-fossil energy to $11.4 \%$ of total energy use and $17 \%$ reduction in carbon intensity by regulating industries in adopting these measures. Jingya (2010) explains further that the plan is a representative of China's efforts to rebalance its economy, shifting emphasis from investment towards consumption and development from urban and coastal areas toward rural and inland areas. While some targets of the plan are largely in line with the status quo, other aspects of the plan represent more drastic moves to reduce fossil energy consumption, promote low-carbon energy sources, and restructure China's economy through an industrial policy. To achieve this, three active components comes into play and the plan's regulation is in order to achieve the set targets. These components are the principal factor, energy, the causal factor which is the industrial sector; hence the industrial policy and the resultant factor which is carbon emission.

\subsubsection{The Principal factor (Energy)}

The relationship between energy and economic growth matters greatly in China as both phenomena simultaneously rise. In the matter of the close relationship between these two, energy consumption and the resultant emission of $\mathrm{CO} 2$ regulations or policies needed to be established. Greenhouse gas emissions from human activities have been the principal driver of climate change. Majority of these emissions have come from China, which has had the world's largest carbon footprint since 2004 and was responsible for $28.5 \%$ of global carbon dioxide emissions even in 2018 (CPP, 2018).

The 12th Five Year Plan set an assertive goal, for which the adjustment of energy consumption structure should make significant progress during the period of 2011-2015. In retrospection to the 11th Five-Year Plan (2006-2010), there was a target to reduce the total energy intensity of the economy by $20 \%$ according to draft guidelines submitted to the 2006 National People's Congress session. Economic growth was to hit a GDP of $7.5 \%$ annually from 18.2 trillion yuan in 2005 to 26.1 trillion yuan in 2010. This target was implemented in response to increases in energy intensity experienced between 2002 and 2005, the first increase experienced after several decades of rapidly decreasing energy intensity. The government mobilized a national campaign to promote energy efficiency, targeting in particular the largest and least efficient energy consuming enterprises in order to reverse the unexpected increases in energy intensity. The 12th FYP builds directly on the 11th FYP energy intensity target and its associated programs, setting a new target to reduce energy intensity by an additional $16 \%$ by 2015 . Jiabao (2011) states that the closure of inefficient power and industrial facilities also helped contribute to the decline in energy intensity during the 11th FYP period, with a reported $72.1 \mathrm{GW}$ of thermal capacity closed. 
There is no doubt, however, that much was learned and there were efforts to improve efficiency nationwide. Many changes were made to the national targets enforced at the local level, including the incorporation of compliance with energy intensity targets into the evaluation for local officials. The 12th FYP includes a target to increase non-fossil energy sources (including hydro, nuclear and renewable energy) to $11.4 \%$ of total energy use (up from $8.3 \%$ in 2010). The government reduced GDP growth rates, targeting $7 \%$ per year. Lower GDP growth rates makes it even more challenging for China to meet energy and carbon intensity targets, because energy and carbon need to grow more slowly than GDP for the country to achieve declining energy and carbon intensity (Gov.cn, 2011). By so doing, there was the top 1,000 Program targeted at approximately 1,000 industries which were consuming about one-third of the country's energy for efficiency improvements (Lewis, 2011).

\subsubsection{The causal factor (Industrial Sector)}

The 12th FYP includes many new industrial policies to support clean energy industries and related technologies. Since the foundation of the People's Republic of China, China's energy has primarily come from coal (Govindaraju and Tang 2013). Coal is overwhelmingly abundant and more widely distributed in China in comparison with oil and natural gas (Li and Leung 2012). As such, the 12th FYP policy resolves to develop safe and efficient coal mines, and large coal enterprise groups, and promote the integration of coal resources, and the merger and reorganization of coal mine enterprises. The industrial policy is to strengthen the exploration and development of petroleum and natural gas resources, stabilize domestic petroleum output, and promote the rapid growth of natural gas output, and the development and utilization of unconventional oil and gas resources. Further, to develop clean and efficient large-capacity coal-fired generating sets, giving priority to heat and power cogeneration units in large/medium cities and industrial parks, large coal-fired power stations near coal mines, and integrated coal gangue power stations. Industries targeted include the nuclear, solar, wind and biomass energy technology industries, as well as hybrid energy savings and environmental protection technology industries. These "strategic and emerging" industries are being promoted to replace the "old" strategic industries such as coal and telecom, which are heavily state-owned and have long benefited from government support.

\subsubsection{The resultant factor (Carbon emission)}

The United Nations Framework Convention on Climate Change (UNFCCC, 2015) sets a good precedence for regulation into climate change by any country. The UNFCCC objective is to "stabilize greenhouse gas concentrations in the atmosphere at a level that would prevent dangerous anthropogenic interference with the climate system"(UNFCCC, 1992, p 9). China Power Team (2018) stipulates that China's economic growth has primarily been powered by coal, which constituted an average of $69.9 \%$ of the country's energy consumption between 1985 and 2016. Burning coal comes at a steep environmental cost, as it produces up to twice the amount of carbon dioxide (CO2) as other fossil fuels. While there has been a slow nationwide coal usage since 2008, China still consumed more coal than the rest of the world combined in 2018. Lewis (2011) also notes that in the lead-up to the Copenhagen climate negotiations in the fall of 2009, the Chinese government pledged a $40-45 \%$ reduction in the national carbon intensity from 2005 levels by 2020. To be in line with this target, the 12th FYP sets an interim target of reducing carbon intensity by $17 \%$ from 2010 levels by 2015 . Whether this target will result in a deviation from China's expected carbon emissions over this time period depends on the corresponding GDP growth and additional policies to promote low carbon energy development.

The 12th FYP therefore goes ahead to establish the goal of gradually establishing a carbon trade market. By so doing, a handful of provinces announced interest in piloting carbon trading schemes. Implementing a carbon trading scheme in China, even on a small-scale or pilot basis came with certain challenges as concerns have already been raised from both domestic and foreign-owned enterprises operating in China about how the regulation could affect their activities. But the key challenge is likely technical, resulting from the minimal capacity currently in place to measure and monitor carbon emissions in China. The 12th FYP, therefore implemented a massive reduction in energy consumption intensity and carbon dioxide emissions by binding targets to efficiently control greenhouse gas emissions. This plan reasonably restricts energy consumption, decrease the growth of industries with high energy consumption, and increase energy efficiency. The plan strengthens energy conservation assessment responsibilities, complete energy-saving regulations and standards, improve market mechanisms and implement pivotal energy-saving projects. It popularizes advanced energy-saving technologies, accelerate the application of the Energy management Contract, and pay adequate attention to industries such as construction and transportation.

\subsection{The triple bottom line of the 12th Final Year Plan.}

In a country such as China, industries and firms are held responsible for their environmental and social performance apart from their economic performance. Consequently, responsibility lies on stakeholders on maintaining sustainable operations. Sustainability concerns of a country are not limited to the boundaries of individual organizations but every citizen and the government. Triple bottom line (TBL) is a theoretical and accounting model that expands the traditional reporting framework to take into account of social and environmental performance in addition to economic performance. This is a popular framework used for evaluating sustainability 
of the organizations, in this case country. The framework makes an organization (country) understand sustainability, at a broader level in three components namely the natural environment, society and economic performance (Carter and Rogers, 2008). As coined by John Elkington (1994), he emphasized that "Sustainable development involves the simultaneous pursuit of economic prosperity, environmental quality, and social equity and the positive correlation of the 12th FYP and the triple bottom line is as follows.

\subsubsection{Economic prosperity}

According to Gang (2011), the targets for the 12th Five-Year Plan in terms of the economy were to grow GDP by around $8 \%, 7 \%$ annual growth of per capita income, spend 2.2\% of GDP on research and development by 2015 . Also, the plan was to bring the population below 1.39 billion by 2015 , readjust income distribution to stop the yawning gap, firmly curb excessive rise of housing prices, implement prudent monetary policy, intensify anticorruption efforts, accelerate economic restructuring, and deal with the complex situations in development in 2011. In doing this, the plan aimed at seeking what its terms "inclusive growth" - rebalancing the economy to spread the benefits more equally, as well as alleviating social inequality and protecting the environment (Boyd \& Copsey, 2011). With the triple-bottom-line model, it is understood that the profit or economic bottom line deals with the economic value created by the organizations (country) after deducting the cost of all inputs of production. In the case of China, after the high energy consumption from previous years plan, example, energy consumption per unit of GDP down was $20 \%$ in the 11 th FYP, the follow up year plan regulated the energy consumption and in doing so, several economic projects such as income redistribution were instituted. This was a means of giving back to the country or society for the all consequences caused by the energy consumption. The greater picture here to achieve sustainability after "profit" is made, and this is seen as the real economic benefit enjoyed by the society. This is the real economic impact the government has on its economic environment. Therefore, as the triple bottom line approach implies, not just a traditional corporate accounting profit with a social and environmental impacts but rather proposes a responsibility of ensuring an economic prosperity for the society and the 12th Final Year Plan completely executed this function.

4.3.2 Social equity

For social equity to be achieved, goals of addressing rising inequality and creating an environment for more sustainable growth by prioritizing more equitable wealth distribution, increased domestic consumption, and improved social infrastructure and social safety and benefits are necessary. The 12th Final Year Plan social equity as an element of the triple bottom line states that urbanization rate should be reaching $51.5 \%$, 36 million new affordable apartments for low-income people should be built. Wong (2010), explains that the plan is representative of China's efforts to rebalance its economy, shifting emphasis from investment towards consumption and development from urban and coastal areas toward rural and inland areas initially by developing small cities and greenfield districts to absorb coastal migration. The plan also continues to advocate objectives set out in the 11 th Five-Year Plan to enhance environmental protection, accelerate the process of opening and reform, and emphasize Hong Kong's role as a center of international finance (Jingya, 2010).

The people, social equity, or human capital bottom line pertains to fair and beneficial business practices toward the community and region in which a corporation conducts its business. An enterprise dedicated to the triple bottom line seeks to provide benefit to many constituencies and not to exploit or endanger any group of them. The upstreaming of a portion of profit from the marketing of finished goods back to the original producer of raw materials, for example, a farmer in fair trade agricultural practice for example, is a feature of this concept. In concrete terms a Triple Bottom Line model typically seeks to "give back" by contributing to the strength and growth of a community with such things as health care and education. If there is an imbalance of social equity and the rich get richer and the poor get both poorer, the chances that society itself will collapse in anger and revolution increase. In world history, however, such revolutions are quite common and that doesn't mean revolution is coming to developed nations. It may indicate, however, that for an organization (country) to be stable over the long term, opportunities and subsequently wealth need to be spread out to cover as many people as possible. China has enjoyed a stable government for a very long time and the greater of the reason lies in the social equity that has been achieved over the years.

\subsubsection{Environmental Quality}

Environmental pollution due to carbon emission has been a consequence of the energy consumption in China. Using the triple bottom line approach, the 12th Final Year Plan was enshrined with ways to achieve environmental quality. Boyd \& Copsey (2011) summarized the environmental quality of the plan as a $16 \%$ cut in energy, $17 \%$ cut in carbon intensity (carbon emitted per unit of GDP) and a boost in non-fossil fuel energy sources to $11.4 \%$ of primary energy consumption (it is currently $8.3 \%$ ). In pollution, there was an $8 \%$ reduction target for sulphur dioxide and chemical oxygen demand and a $10 \%$ reduction target for ammonia nitrogen and nitrogen oxides, the latter of which came mainly from China's dominant coal sector. Water intensity (water consumed per unit of valueadded industrial output) was set to be cut by $30 \%$ by 2015 , China also aimed to boost forests by 600 million cubic meters and forest cover to $21.66 \%$ (Boyd \& Copsey, 2011). This situation goes a long way to influence the climate and atmosphere to support the continuous living in society. Through the assumptions of the triple bottom line 
there is an affirmation that for instance natural resources especially the oil fueling the engines, clean air, and water should be prioritized. If these essential elements of society are deteriorated, generations of people will not enjoy a quality of life being experienced. Conservation of resources, therefore, becomes tremendously important, as does the development of new sources of energy that may substitute those we're currently using. Under these circumstances, the 12th Final Year Plan executed its set objectives by investing in its own renewable energy sector and demonstrating to the world that China is committed to environmental protection. This goes further to remind the rest of the world of the fact that achieving green growth should be a gradual, determined and continuous process.

\section{Conclusion}

In a nutshell, this paper describes China as a stable economy, a power hub of energy, a potential advocate of environmental awareness and an achiever of green growth. The ultimate social responsibility of a government has been executed through the theory of triple bottom line which underlines the 12th Final Year Plan. With the 13th Final Year Plan lingering around to conclude by close of 2020, it is predicted to achieve the development of environmental technology industry, as well as ecological living and ecological culture to further sustain a green economy. The 12th FYP provides a clear clue into how China's leadership laid out an important step in moving the country into green growth. This includes a strong dependence on new forms of energy and climate programs and clearly illustrates China's commitment to increased environmental protection. With the assumptions of the triple bottom line theory as the foundation of the plan, there was the adjustment of the economic structure as a way to achieve a legally binding targets on energy-intensity and carbon-intensity reduction which should be both ambitious and robust in its implementation. Therefore, the social equity, economic growth and environmental development gives a robust and promising future for China's energy generation and usage.

\section{References}

Andrews-Speed, P. (2014). "China's Energy Policymaking Processes and Their Consequences". The National Bureau of Asian Research Energy Security Report. Retrieved December 5, 2014.

Arora, N.K. (2018). "Environmental Sustainability-necessary for survival". Environmental Sustainability 1, 12. https://doi.org/10.1007/s42398-018-0013-3.

Bilgen, S. (2014). "Structure and environmental impact of global energy consumption". Renew Sustain Energy Rev. 2014;38:890-902. doi:10.1016/j.rser.2014.07.004. 226.

Boyd, O \& Copsey, T. (2011). China's Green Growth Revolution: Energy, Environment and the 12th Five-Year Plan. Retrieved on 7th February, 2020.

Brandt, L. et al. (2008). China's Great Transformation. Cambridge: Cambridge university press.

Búriková, Z. (2012). Consumer Culture: History, Theory and Politics by Roberta Sassatelli/Gender and Consumption: Domestic Cultures and the Commercialisation of Everyday Life edited by Emma Casey and Lydia Martens/Buying for the Home: Shopping for the Domestic from the Seventeenth Century to the Present edited by David Hussey and Margaret Ponsonby. 9(1), 105-111. doi:10.2752/175174212x13202276383931

Buhl, C., (2005): "Det lærende brand". Kbh.: Børsens Forlag.

Carter, C.R., \& Rogers, D.S. (2008). A Framework of Supply Chain Management: Moving toward New Theory. International Journal of Physical Distribution and Logistics Management, 38(5), 360387.https://doi.org/10.1108/09600030810882816.

China Power Team. "How is China's energy footprint changing?" China Power. February 15, 2016. Updated March 19, 2020. Accessed May 29, 2020. https://chinapower.csis.org/energy-footprint/.

China Power Team. "How is China managing its greenhouse gas emissions?" China Power. July 19, 2018. Updated February 11, 2020. Accessed February 13, 2020. https://chinapower.csis.org/china-greenhouse-gasemissions/

Chan, C. K., \& Yao, X. (2008). “Air pollution in mega cities in China”. Atmospheric.41-42.

Czarnecka, B. \& Schivinski, B. (2019). "Do Consumers Acculturated to Global Consumer Culture Buy More Impulsively? The Moderating Role of Attitudes towards and Beliefs about Advertising". Journal of Global Marketing.

"Constitution of the People's Republic of China". www.constituteproject.org. Retrieved 17 January 2020

Csaba, F.F. \& Bengtsson, A. (2006): "Rethinking Identity in Brand Management”, in: Schroeder, J.E. \& SalzerMörling, M., eds. (2005): Brand Culture. London \& New York: Routledge.

Elkington, J. (2018). "25 Years Ago I Coined the Phrase "Triple Bottom Line." Here's Why It's Time to Rethink It". Harvard Business Review. Retrieved October 11, 2019.

Gang, P (2011). "China's Wen delivers key targets of its development". International Business Times. Archived from the original on 19 March 2011. Retrieved 5 March 2011.

Goel, P. (2010). "Triple bottom line reporting: An analytical approach for corporate sustainability". Journal of Finance, Accounting, and Management, 1(1), 27-42.

Govindaraju, V. C \& Tang, C.F (2013). "The dynamic links between CO2 emissions, economic growth and coal 
consumption in China and India”. Appl Energy.104:310-8. doi:10.1016/j.apenergy.2012.10.042.

Hays, J. (2008) Environmental problems in china, pollution and health problems. Retrieved November, 2019.

Hong-Dian, J. et, al. (2016) A review of China's energy consumption structure and outlook based on a long-range energy alternatives modeling tool. Springerlink.com DOI 10.1007/s12182-016-0136-z.

Jingya, Z. (2010). "China unveils 12th Five-Year Plan". CNTV. Archived from the original on 1 November 2010. Retrieved 3rd February, 2020.

Kroeber, A. R (2016). China's economy: what everyone needs to know. New York, NY: Oxford University Press. pp. 210-4. ISBN 9780190239039. OCLC 945553795.

Levy, S. (1959) "Symbols for Sale”. Harvard Business Review, jul/aug 1959, vol. 37.

Lewis, J. (2011). Energy and Climate Goals of China's 12th Five-Year. Retrieved online at https://www.c2es.org/document/energy-and-climate-goals-of-chinas-12th-five-year-plan.

Li, R. \& Leung, G.C. (2011). Coal consumption and economic growth in China. Energy Policy. 2012;40:438-43. doi:10.1016/j.enpol.2011.10.034.

Liu, L.et al. (2011). China's carbon emissions from urban and rural households during 1992 2007. J. Clean. Prod. 2011.

Ma, D. \& Chen, W. (2016). Analysis of China's 2030 carbon emission peak level and peak path. China Popul Resource Environ. 26(5):1-4. Chinese.

McGrath, Matt (November 20, 2019). "China coal surge threatens Paris climate targets". Retrieved December 9, 2019.

Rennings K, Brohmann B, Nentwich J, et al. (2012). Sustainable energy consumption in residential buildings. New York: Springer.

Saidi, K., \& Hammami, S. (2015a), The impact of energy consumption and CO2 emissions on economic growth: Fresh evidence from dynamic simultaneous-equations models. Sustainable Cities and Society, 14, 178-186.

Saidi, K., \& Hammami, S. (2015b), The impact of CO2 emissions and economic growth on energy consumption in 58 countries. Energy Reports, 1, 62-70.

Sassatelli, R. (2007). Consumer Culture_History, Theory and Politics-Sage Publications Ltd. page 125

Siu, Tyrone (2015). "World's largest electronics waste dump in China". news.trust.org. Thomson Reuters Foundation.

Slaper, T. F., \& Hall, T. J. (2011). "The Triple Bottom Line: What Is It and How Does It Work?" Indiana Business Review. Spring 2011, Volume 86, No.

Spangenberg, J. (2005). Economic sustainability of the economy: Constructs and indicators. International Journal of Sustainable Development, 8(1/2), 47-64. http://dx.doi.org/10.1504/IJSD.2005.007374

Städtler, R. (2011). Celebrity Scandals and their Impact on Brand Image: A Study among Young Consumers: A Theoretical and Empirical Investigation. GRIN Verlag. p. 16.

Sun, J., \& Ryder, A. G. (2016). The Chinese Experience of Rapid Modernization: Sociocultural Changes, Psychological Consequences. Frontiers in psychology.

The United Nations Framework Convention on Climate Change (1992). Retrieved 23 May 2016.

UNFCCC, 2015. The Paris Agreement. United Nations Framework Convention on Climate Change, Paris, France.

Walder, A. G. (2015). China Under Mao. Cambridge, MA: Harvard University Press

World Nuclear Association (2007). Nuclear Power in China at the Wayback Machine. Archived 12 February 2013.

Wong, A. (2010). "China to further strengthen HK's role in 12th Five-Year Plan". International Business Times. Archived from the original on 23 December 2010. Retrieved 22 December 2010.

Wong, E. (2013). "Cost of Environmental Damage in China Growing Rapidly Amid Industrialization". The New York Times. Retrieved 30 March 2019.

White, S. \& Denis, P (2019). Louis Vuitton sees demand in mainland China picking up steam. Retrieved online at https://www.reuters.com/article/us-lvmh-vuitton-china/louis-vuitton-sees-demand-in-mainland-chinapicking-up-steam.

Xin, Z. (2019). China's energy consumption hits five-year record. https://www.chinadaily.com.cn/a/201904/28/WS5cc59903a3104842260b8ed7.html

Yongsheng, Z. (2011). The impact of China's 12th Five Year Plan. Economics, Politics and Public Policy in East Asia and the Pacific. Accessed online https://www.eastasiaforum.org/2011/04/24/the-impact-of-china-s12th-five-year-plan/

"China announces 16 pet cut in energy consumption per unit of GDP by 2015," Gov.cn, March 5, 2011. http://www.gov.cn/english/2011-03/05/content_1816947.htm; "Zhang: „Twelfth Five ee push to non-fossil energy to account for 11.4 percent share of primary energy” (张国宝: “十二五”末力争非化石能源占一次 能源比重 11.4\%), people.com.cn, January 6, 2011. http://energy.people.com.cn/GB/13670716.html 